\title{
Secondary surgical-site infection after coronary artery bypass grafting: A multi-institutional prospective cohort study
}

Brian C. Gulack, MD, MHS, ${ }^{a}$ Katherine A. Kirkwood, MS, ${ }^{c}$ Wei Shi, MS, ${ }^{c}$ Peter K. Smith, MD, ${ }^{a}$ John H. Alexander, MD, MHS, ${ }^{b}$ Sandra G. Burks, RN, BSN, CCRC, ${ }^{d}$ Annetine C. Gelijns, PhD, Vinod H. Thourani, MD, ${ }^{e}$ Daniel Bell, MS, ${ }^{\mathrm{f}}$ Ann Greenberg, RN, MSN, ${ }^{\mathrm{g}}$ Seth D. Goldfarb, ${ }^{\mathrm{c}}$ Mary Lou Mayer, RN, BSN, CCRN, ${ }^{\text {h }}$ and Michael E. Bowdish, MD, ${ }^{\mathrm{i}}$ for the Cardiothoracic Surgical Trials Network (CTSN)

\section{ABSTRACT}

Objective: To analyze patient risk factors and processes of care associated with secondary surgical-site infection (SSI) after coronary artery bypass grafting (CABG).

Methods: Data were collected prospectively between February and October 2010 for consenting adult patients undergoing CABG with saphenous vein graft (SVG) conduits. Patients who developed a deep or superficial SSI of the leg or groin within 65 days of CABG were compared with those who did not develop a secondary SSI.

Results: Among 2174 patients identified, 65 (3.0\%) developed a secondary SSI. Median time to diagnosis was 16 days (interquartile range 11-29) with the majority $(86 \%)$ diagnosed after discharge. Gram-positive bacteria were most common. Readmission was more common in patients with a secondary SSI (34\% vs $17 \%$, $P<.01)$. After adjustment, an open SVG harvest approach was associated with an increased risk of secondary SSI (adjusted hazard ratio [HR], 2.12; 95\% confidence interval $[\mathrm{CI}], 1.28-3.48$ ). Increased body mass index (adjusted HR, 1.08, 95\% CI, 1.04-1.12) and packed red blood cell transfusions (adjusted HR, 1.13; $95 \%$ CI, 1.05-1.22) were associated with a greater risk of secondary SSI. Antibiotic type, antibiotic duration, and postoperative hyperglycemia were not associated with risk of secondary SSI.

Conclusions: Secondary SSI after CABG continues to be an important source of morbidity. This serious complication often occurs after discharge and is associated with open SVG harvesting, larger body mass, and blood transfusions. Patients with a secondary SSI have longer lengths of stay and are readmitted more frequently. (J Thorac Cardiovasc Surg 2018;155:1555-62)

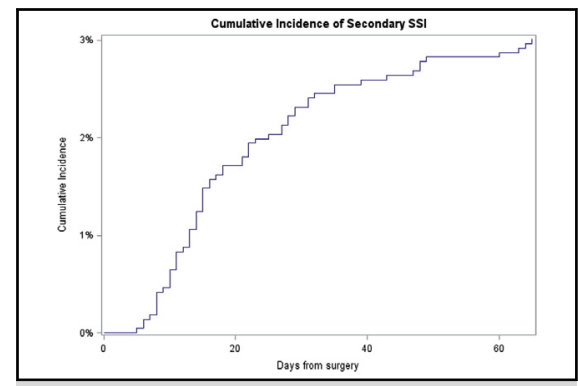

Cumulative incidence of secondary SSI by time from index procedure.

Central Message

Secondary surgical-site infections after coronary artery bypass grafting are neither uncommon nor trivial and often require hospital readmission.

Perspective

Deep and superficial secondary surgical-site infections after coronary artery bypass grafting are serious complications that often occur after initial hospital discharge and require readmission. Patients who undergo open harvesting of the saphenous vein, have a greater body mass index, and receive more packed red blood cells are at greater risk.

See Editorial Commentary page 1563.

\footnotetext{
From the a Division of Cardiovascular and Thoracic Surgery, Department of Surgery, and ${ }^{b}$ Division of Cardiology, Duke Clinical Research Institute, Duke Health, Durham, NC; ${ }^{\mathrm{c} I n t e r n a t i o n a l ~ C e n t e r ~ f o r ~ H e a l t h ~ O u t c o m e s ~ a n d ~ I n n o v a t i o n ~ R e s e a r c h ~}$ (InCHOIR) in the Department of Population Health Science and Policy, Icahn School of Medicine, New York, NY; ${ }^{\mathrm{d}}$ Division of Thoracic and Cardiovascular Surgery, University of Virginia, Charlottesville, Va; ${ }^{\mathrm{e}}$ Department of Cardiac Surgery, MedStar Heart and Vascular Institute, Washington Hospital Center, Washington, DC; ${ }^{\mathrm{f}}$ Division of Cardiothoracic Surgery, Columbia University Medical Center, New York, NY; ${ }^{g}$ Department of Cardiothoracic Surgery, NIH Heart Center at Suburban Hospital, Bethesda, Md; ${ }^{\mathrm{h}}$ Department of Surgery, Division of Cardiovascular Surgery, University of Pennsylvania School of Medicine, Philadelphia, Pa; and the ${ }^{\mathrm{i}}$ Department of Surgery, Keck School of Medicine of USC, University of Southern California, Los Angeles, Calif.
}

Clinical Trial Registry Number: NCT01089712.

Sources of Funding: A cooperative agreement (U01 HL088942) funded by the National Heart, Lung, and Blood Institute and the National Institute of Neurological Disorders and Stroke of the National Institutes of Health and the Canadian Institutes of Health Research.

Received for publication Dec 15, 2016; revisions received Oct 6, 2017; accepted for publication Oct 23, 2017; available ahead of print Dec 6, 2017.

Address for reprints: Annetine C. Gelijns, PhD, Department of Population Health Science and Policy, Icahn School of Medicine at Mount Sinai, One Gustave L. Levy Place, Box 1077, New York, NY 10029 (E-mail: annetine.gelijns@mssm.edu). 0022-5223/\$36.00

Copyright (c) 2017 by The American Association for Thoracic Surgery

https://doi.org/10.1016/j.jtcvs.2017.10.078 


$$
\begin{aligned}
& \text { Abbreviations and Acronyms } \\
& \begin{aligned}
\text { BMI } & =\text { body mass index } \\
\text { CABG } & =\text { coronary artery bypass grafting } \\
\text { CI } & =\text { confidence interval } \\
\text { CTSN } & =\text { Cardiothoracic Surgical Trials Network } \\
\text { HR } & =\text { hazard ratio } \\
\text { IQR } & =\text { interquartile range } \\
\text { PRBC } & =\text { packed red blood cell } \\
\text { SSI } & =\text { surgical-site infection } \\
\text { SVG } & =\text { saphenous vein graft }
\end{aligned}
\end{aligned}
$$

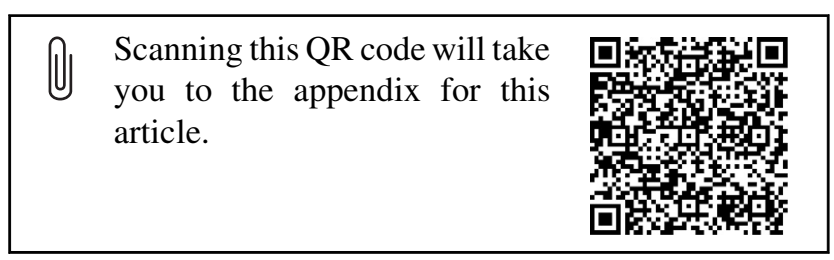

Despite improvements in medical care and the increased emphasis on quality improvement programs to reduce postoperative infections, nearly $5 \%$ of patients experience major infection after cardiac surgery. ${ }^{1}$ In recently published findings from a prospective, multi-institutional cohort study of infections associated with cardiac surgery, researchers observed substantial increases in morbidity, mortality, and costs associated with these events. ${ }^{1,2}$ However, secondary surgical-site infections (SSIs) in patients who undergo coronary artery bypass grafting (CABG) with saphenous vein graft (SVG) harvesting were one infection of interest not analyzed in this initial report.

SSIs of the SVG harvest site after CABG affect $1 \%$ to $4 \%$ of patients and are associated with substantial morbidity and cost. ${ }^{3-5}$ In rare cases, these infections can even lead to limb loss. ${ }^{5}$ Although numerous outcome studies after saphenous vein harvesting have been reported, few focus on infection as the primary endpoint, and those that do frequently lack follow-up past discharge or 30 days postoperatively, are nonadjudicated, and are frequently retrospective single-center analyses. ${ }^{4,6-20}$

In this study, using data previously collected by the Cardiothoracic Surgical Trials Network (CTSN), we aimed to characterize secondary SSIs of the leg or groin in patients undergoing $\mathrm{CABG}$ with saphenous vein conduits and to analyze patient risk factors and processes of care associated with these infections.

\section{METHODS}

\section{Patient Population}

As previously published, all consenting adult cardiac surgery patients at CTSN sites without an active systemic infection were enrolled in the prospective observational study "Management Practices and the Risk of
Infections following Cardiac Surgery" (see Appendix E1 for list of sites). We selected all patients in the CTSN study who underwent a CABG procedure (with or without concomitant procedures) with saphenous vein conduit harvesting $(n=2174$, Figure 1$)$.

\section{Study Design}

Baseline and operative characteristics, process of care data, and postoperative complications were captured up to 65 days postprocedure as part of the CTSN infection study. The primary outcome of interest in this analysis was the incidence of SSI of the secondary incision site in the leg or groin (eg, saphenous vein harvest site, perfusion cannulation site). Secondary SSIs were categorized as deep or superficial. A secondary SSI was defined as an infection that occurred within 65 days of the procedure, involved the deep soft tissues of the incision (deep SSI) or the skin and subcutaneous tissue (superficial SSI), and had at least 1 of the following: purulent discharge; a spontaneous incisional dehiscence or an incision opened in response to fever or localized pain/tenderness and with a positive culture or without a culture in the presence of fever, localized pain, and/or tenderness; an abscess or other evidence of infection found on direct examination, during reoperation or by histopathologic or radiologic examination; or a diagnosis of an incisional SSI by the physician. Data related to the time to onset of secondary SSI, risk factors potentially affecting the incidence of SSIs, and microbial isolates related to the SSIs were also analyzed.

\section{Statistical Analysis}

Patients who did and did not develop a secondary SSI were compared with regard to baseline characteristics, operative characteristics, postoperative management, and outcomes. Continuous variables were compared with a $t$ test (for means) or Wilcoxon-Mann-Whitney $U$ test (for medians), whereas categorical variables were compared with the $\chi^{2}$ test or Fisher exact test as appropriate. A Cox proportional hazards regression model of time to secondary SSI was built by the use of backwards stepwise regression; death was accounted for as a competing risk. ${ }^{21}$ Variables found to be associated with a secondary SSI (at $P<.20$ ) on univariable analysis were considered for inclusion in the multivariable model; all variables in the final model were significant at the $P \leq .05$ level. Complete case analysis was used for all adjusted models. Although frequency of use of vein graft harvest technique varied widely by site, with most open harvests in Canada, we adjusted for patient-level risk factors and management practices rather than by site to avoid obscuring these risks. All statistical analyses were performed with SAS statistical software (version 9.4; SAS Institute, Inc, Cary, NC).

\section{RESULTS \\ Incidence of SSIs}

A total of 2174 patients underwent CABG with SVG harvesting, of whom $65(3.0 \%)$ developed a secondary SSI within 65 days of the index operation. The cumulative incidence of secondary SSIs of the leg or groin by time from index procedure is shown in Figure 2. Median time to secondary SSI was 16 days (interquartile range [IQR], 1129). The majority of these infections were diagnosed after discharge from the index hospitalization $(\mathrm{n}=56,86 \%)$, most within 30 days of discharge $(n=46,82 \%)$.

Of the secondary SSIs, 8 (12\%) were defined as deep, whereas $57(88 \%)$ were defined as superficial. The median time to a deep secondary SSI was 27 days (IQR, 14-44), whereas the median time to a superficial secondary SSI was 15 days (IQR, 11-28). No patient with a superficial infection progressed to a deep infection. 


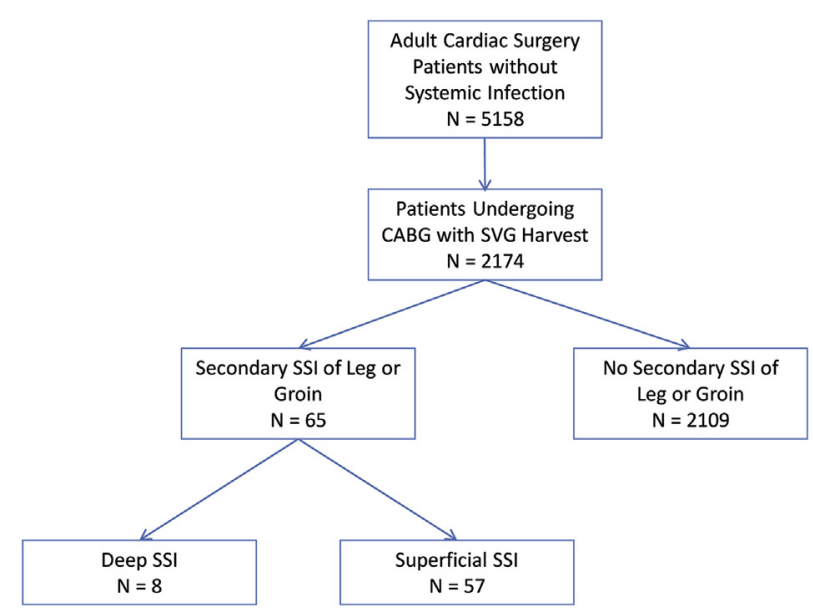

FIGURE 1. Consolidated Standards of Reporting Trials diagram. $C A B G$, Coronary artery bypass grafting; $S V G$, saphenous vein graft; SSI, surgicalsite infection.

\section{Factors Associated With SSIs}

Baseline characteristics between those with and without a secondary SSI are shown in Table 1. With the exception of body mass index (BMI), baseline demographics and cardiac and noncardiac morbidities were similar between groups. BMI was significantly associated with a greater rate of secondary SSI (median BMI among patients who developed and those who did not develop a secondary SSI: 31 vs $\left.29 \mathrm{~kg} / \mathrm{m}^{2}, P<.01\right)$.
Operative characteristics including type of procedure (isolated $\mathrm{CABG}, \mathrm{CABG}+$ valve, $\mathrm{CABG}+$ other), urgency of surgery, operative time, cardiopulmonary bypass time, and number of vein anastomoses were not significantly different between groups (Table 2). Most patients $(\mathrm{n}=2171,99.9 \%)$ had a sternotomy as the primary incision. Endoscopic vein harvesting was less frequently used in patients with secondary SSI $(60.0 \%$ vs $75.6 \%, P<.01)$.

Furthermore, patients who developed a secondary SSI were significantly more likely to have received a larger transfusion of packed red blood cells (PRBCs) during their index hospitalization than patients who did not develop an SSI (median [IQR] 2 units [0-4] vs 1 unit [0-3], $P=.05$ ). Preoperative anemia did not affect risk of infection $(P=.87)$ or modify the risk associated with transfusion $(P=.69)$. There were no significant differences in infection rates with regard to type of surgical scrub (chlorhexidine or other), type of antibiotic given (second generation cephalosporin or other), duration of antimicrobial therapy postoperatively, or presence or absence of postoperative hyperglycemia.

Factors associated with the development of a secondary SSI in multivariable analysis treating death as a competing risk are shown in Figure 3. The use of an open approach (adjusted hazard ratio [HR], 2.12, 95\% confidence interval $[\mathrm{CI}], 1.28,3.48)$ remained associated with secondary SSIs. Increased BMI (adjusted HR per $\left.\mathrm{kg} / \mathrm{m}^{2}, 1.08 ; 95 \% \mathrm{CI}, 1.04-1.12\right)$ and $\mathrm{PRBC}$

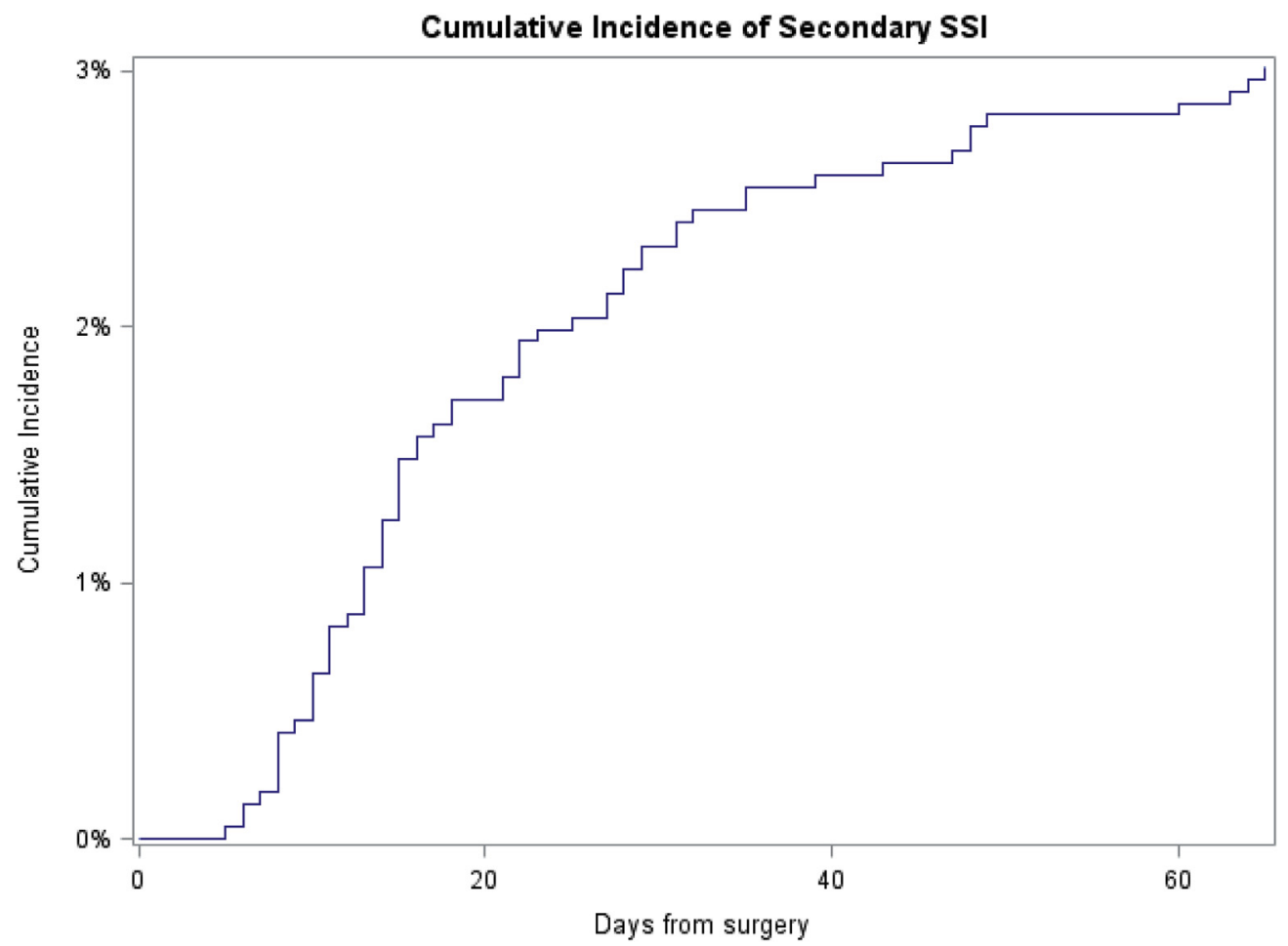

FIGURE 2. Cumulative incidence of secondary SSI of the leg or groin in patients undergoing coronary artery bypass grafting with saphenous vein harvesting by time from index procedure. SSI, Surgical-site infection. 
TABLE 1. Baseline characteristics of patients undergoing CABG with SVG harvesting with and without secondary SSI*

\begin{tabular}{|c|c|c|c|c|}
\hline & Overall $(n=2174)$ & Secondary SSI $(n=65)$ & No secondary SSI $(n=2109)$ & $P$ value \\
\hline \multicolumn{5}{|l|}{ Demographics } \\
\hline Age, y & $67(10.5)$ & $68(9.9)$ & $67(10.5)$ & .53 \\
\hline Male & $1632(75.1)$ & $46(70.8)$ & $1586(75.2)$ & .42 \\
\hline White & $1754(80.8)$ & $56(86.2)$ & $1698(80.6)$ & .26 \\
\hline Body mass index, $\mathrm{kg} / \mathrm{m}^{2}$ & $29(26,33)$ & $31(28,37)$ & $29(26,33)$ & $<.01$ \\
\hline \multicolumn{5}{|l|}{ Cardiac morbidity } \\
\hline Heart failure & $578(26.6)$ & $23(35.4)$ & $555(26.3)$ & .10 \\
\hline Ejection fraction & $55(45,60)$ & $55(45,60)$ & $55(45,60)$ & .83 \\
\hline Previous cardiac surgery & $231(10.6)$ & $9(13.9)$ & $222(10.5)$ & .39 \\
\hline Peripheral vascular disease & $309(14.2)$ & $13(20.0)$ & $296(14.0)$ & .17 \\
\hline \multicolumn{5}{|l|}{ Noncardiac morbidity } \\
\hline Smoking history & $1169(53.8)$ & $41(63.1)$ & $1128(53.5)$ & .13 \\
\hline Hypertension & $1825(84.0)$ & $58(89.2)$ & $1767(83.8)$ & .24 \\
\hline Hyperlipidemia & $1696(78.1)$ & $57(87.7)$ & $1639(77.8)$ & .06 \\
\hline Diabetes $\dagger$ & $724(33.3)$ & $26(40.0)$ & $698(33.1)$ & .24 \\
\hline Renal insufficiency & $306(14.1)$ & $13(20.0)$ & 293 (13.9) & .16 \\
\hline Corticosteroids & $68(3.1)$ & $4(6.3)$ & $64(3.0)$ & .14 \\
\hline
\end{tabular}

SSI, Surgical-site infection. *Continuous variables are expressed as mean (SD) or median (IQR), as appropriate, and categorical variables as count (\%). †Insulin or oral medications.

transfusion (adjusted HR per unit, 1.13; 95\% CI, 1.05-1.22) both remained associated with a greater incidence of secondary SSIs. Neither the duration of postoperative antibiotics, type of antibiotics given, nor presence or absence of postoperative hyperglycemia was associated with a significant increase or decrease in secondary SSIs with multivariable modeling. A sensitivity analysis of US patients alone with predominantly endoscopic vein harvest confirmed the risk associated with increased BMI and PRBC transfusion.

TABLE 2. Operative and process-of-care characteristics of patients undergoing CABG with SVG harvesting with and without secondary SSI*

\begin{tabular}{|c|c|c|c|c|}
\hline & Overall $(n=2174)$ & Secondary SSI $(n=65)$ & No secondary SSI $(n=2109)$ & $P$ value \\
\hline \multicolumn{5}{|l|}{ Operative } \\
\hline Procedure & & & & .32 \\
\hline Isolated CABG & $1486(68.4)$ & $48(73.9)$ & $1438(68.2)$ & \\
\hline $\mathrm{CABG}+$ valve & $566(26.0)$ & $12(18.5)$ & $554(26.3)$ & \\
\hline Other & $122(5.6)$ & $5(7.7)$ & $117(5.5)$ & \\
\hline Surgery type & & & & .71 \\
\hline Elective & $1411(64.9)$ & $42(64.6)$ & $1369(64.9)$ & \\
\hline Urgent & $692(31.8)$ & $22(33.9)$ & $670(31.8)$ & \\
\hline Emergent & $71(3.3)$ & $1(1.5)$ & $70(3.3)$ & \\
\hline Operative time, $\mathrm{h}$ & $4.5(3.5,5.6)$ & $4.5(3.4,5.7)$ & $4.5(3.5,5.6)$ & .71 \\
\hline Cardiopulmonary bypass & $1914(88.0)$ & $59(90.8)$ & $1855(88.0)$ & .49 \\
\hline Bypass time, $\min \dagger$ & $107(80,138)$ & $106(73,138)$ & $107(80,138)$ & .89 \\
\hline Sternotomy & $2171(99.9)$ & $65(100.0)$ & $2106(99.9)$ & 1.00 \\
\hline Endoscopic SVH & $1633(75.1)$ & $39(60.0)$ & $1594(75.6)$ & $<.01$ \\
\hline No. of vein anastomoses & $2(1,2)$ & $2(1,2)$ & $2(1,2)$ & .58 \\
\hline \multicolumn{5}{|l|}{ Process of care } \\
\hline Packed red blood cells, units & $1(0,3)$ & $2(0,4)$ & $1(0,3)$ & .05 \\
\hline Surgical-site scrub with chlorhexidine & $1721(80.4)$ & $55(84.6)$ & $1666(80.3)$ & .38 \\
\hline Second-generation cephalosporin & $1000(46.0)$ & $28(43.1)$ & $972(46.1)$ & .63 \\
\hline Continuation of antimicrobials & & & & .78 \\
\hline $0-24 \mathrm{~h}$ & $1253(57.6)$ & $40(61.5)$ & $1213(57.5)$ & \\
\hline$>24-48 \mathrm{~h}$ & $791(36.4)$ & $22(33.9)$ & $769(36.5)$ & \\
\hline$>48 \mathrm{~h}$ & $130(6.0)$ & $3(4.6)$ & $127(6.0)$ & \\
\hline Postoperative hyperglycemia & $1070(49.2)$ & $36(55.4)$ & $1034(49.1)$ & .31 \\
\hline
\end{tabular}

SSI, Surgical-site infection; $C A B G$, coronary artery bypass grafting; $S V H$, saphenous vein harvest. ${ }^{*}$ Continuous variables are expressed as median (IQR) and categorical variables

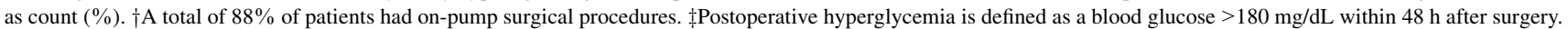




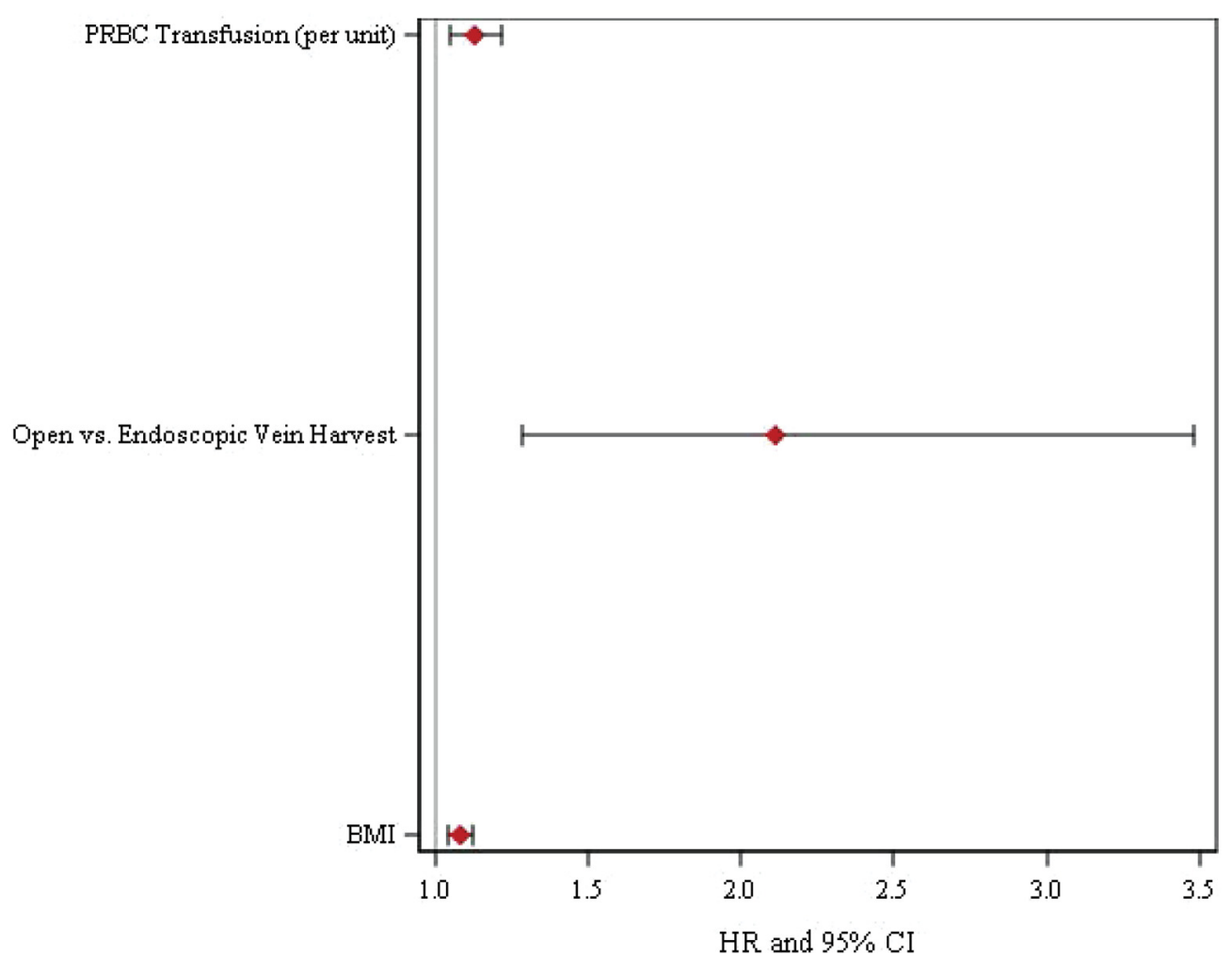

FIGURE 3. Factors associated with the development of a secondary SSI of the leg or groin in patients undergoing CABG with saphenous vein harvesting after multivariable adjustment. PRBC, Packed red blood cells; BMI, body mass index; $H R$, hazard ratio; $C I$, confidence interval.

\section{Organisms Responsible for Secondary SSIs}

Among patients with a deep secondary SSI, 7 (87.5\%) patients had culture data. Equal numbers of Gram-positive and -negative organisms were isolated; one patient had both Gram-positive and Gram-negative bacteria isolated. Bacteria isolated were coagulase-negative staphylococcus (methicillin-resistant Staphylococcus epidermidis), Enterobacter cloacae, Enterococcus $(\mathrm{n}=2)$, Proteus mirabilis, Pseudomonas aeruginosa $(\mathrm{n}=2)$, Staphylococcus aureus (methicillin resistant), and $S$ aureus (methicillin sensitive). There were no fungal deep secondary SSIs. Five patients had a single isolate, whereas 2 had multiple organisms isolated.

Among patients with a superficial secondary SSI, 22 $(38.6 \%)$ had culture data. Gram-positive bacteria were most common $(68 \%)$, although Gram-negative bacteria were not uncommon $(23 \%)$. Candida/mixed skin flora were isolated in 1 patient, and both candida and Gramnegative bacteria were isolated in 1 patient. $S$ aureus was the most common isolate found in 12 patients (two thirds were methicillin resistant and one third were methicillin sensitive). Candida albicans, coagulase-negative staphylococcus $(\mathrm{n}=2)$, Corynebacterium striatum, Enterobacter, Enterococcus $(\mathrm{n}=2)$, Escherichia coli, mixed skin flora, Morganella morganii, Serratia marcescens, $S$ epidermidis (methicillin resistant), Stenotrophomonas, and Streptococcus species were also isolated.

\section{Outcomes}

More patients who developed a secondary SSI were readmitted within 65 days of surgery than patients who did not develop a secondary SSI $(34 \%$ vs $17 \%, P<.01)$. Of 27 readmissions in 23 patients with a secondary SSI who were readmitted, $21(77.8 \%)$ readmissions were due to the secondary SSI. The median length of stay during the rehospitalization was 7 days (IQR, 5-9). There was no significant difference in a low rate of 65-day mortality among patients with and without a secondary SSI $(0.0 \%$ vs $1.9 \%, P=.63)$.

\section{DISCUSSION}

In this large, prospective, multi-institutional cohort study, we demonstrated that secondary SSIs after CABG with SVG conduit are not uncommon, are often diagnosed after initial discharge, and are associated with more frequent hospital readmissions. In addition, SSI occurs with more frequency in those who undergo open saphenous vein harvest, receive more units of PRBCs, and have a greater BMI. Common widely endorsed process-of-care measures, specifically, duration of antibiotic therapy, type of antibiotic prophylaxis, and postoperative glycemic control, were not associated with secondary SSI in this analysis.

The incidence of secondary SSI in this study was $3.0 \%$ at 65 days of follow-up, which, although similar to other recent large observational studies, is greater than the most 
common major infection reported in the CTSN infection study. ${ }^{1,3,4}$ The initial publication from the CTSN reported that nearly $5 \%$ of patients experience a major infection after cardiac surgery, with pneumonia (2.38\%), bloodstream infections $(1.09 \%)$, and $C$ difficile colitis $(0.97 \%)$ being the most common. ${ }^{1}$ Other SSIs reported included deep SSIs of the chest and groin $(0.56 \%$ and $0.21 \%$, respectively) and superficial infections of the chest and groin (2.93\% and $1.56 \%$, respectively). ${ }^{1}$ Although secondary leg and groin-site infections were not included in the original report, the overall incidence is clearly not trivial. The prospective, multicenter nature of this cohort study provides a unique opportunity to characterize these infections.

Like other recent reports, our results show that endoscopic saphenous vein harvesting is associated with a significantly lower incidence of secondary SSI in patients undergoing $\mathrm{CABG}$. Endoscopic saphenous vein harvesting was first introduced in the mid-1990s and is currently estimated to be the method of choice in more than $70 \%$ of CABG procedures in the United States. ${ }^{6-8}$ Three quarters of patients undergoing CABG in this study had endoscopic vein harvesting, of whom $2.4 \%$ developed a secondary SSI, which is less than one half the proportion seen in the open vein harvest group $(4.8 \%, P<.01)$.

Two large recent studies have examined the association of long-term outcomes after endoscopic vein harvesting after CABG. Although both of these studies were conducted to primarily look at long-term consequences of endoscopic versus open saphenous vein harvest in CABG, both also included an examination of saphenous vein graft-site SSIs. Williams and colleagues ${ }^{3}$ conducted a retrospective observational study of 235,394 Medicare patients undergoing isolated CABG between 2003 and 2008 at 934 surgical centers in which data from the Society of Thoracic Surgeons national database were linked to Medicare files to allow longitudinal assessment In this study, $52 \%$ of patients received endoscopic vein-graft harvesting during $\mathrm{CABG}$ surgery. Endoscopic vein-graft harvest was associated with a lower harvest site wound complication rate relative to open vein-graft harvesting at 30 days $(2.97 \%$ compared with $3.60 \%$, risk-adjusted HR, $0.83 ; 95 \%$ CI $, 0.77-0.89, P<.001)$. Dacey and colleagues ${ }^{4}$ reported on 8542 patients who underwent isolated CABG between 2001 and 2004 in which 52.5\% of patients received endoscopic vein-graft harvesting for the Northern New England Cardiovascular Disease Study Group. Endoscopic vein harvesting was also associated a decreased risk of leg wound infections $(0.2 \%$ vs $1.1 \%$, $P<.001)$.

Our results support the hypothesis that the introduction of endoscopic saphenous harvesting has decreased the overall occurrence of these not-trivial, secondary surgical infections. Importantly, our analysis suggests that this benefit extends not only to patients undergoing isolated CABG but also combined and emergent/urgent procedures, as these patients were not excluded in our analysis.

BMI and the need for transfusion of more units of PRBCs were strongly associated with risk of developing a secondary SSI on multivariable modeling, with those of greater BMI being more likely to develop a secondary SSI. This finding is not surprising, given that patients with a greater BMI are generally thought to be at greater risk of postoperative infection and poor wound healing. ${ }^{22,23}$ There are numerous theories as to why this relationship occurs, including reduced wound circulation and oxygenation, as well as increased wound tension. The need for transfusion of PRBCs was also associated with risk of developing a secondary SSI (HR 1.13 per unit, $P<.01$ ) and is consistent with others studies such as that reported by Horvath and colleagues, ${ }^{24}$ in which there was an incremental crude risk for major infection of $29 \%$ for each unit of PRBCs transfused in cardiac surgery. Previous studies have demonstrated blood transfusion may lead to immunomodulatory effects, which may be responsible for the increased incidence of SSI. ${ }^{25}$ Alternatively, blood transfusion may be a surrogate for preoperative anemia, which may also increase the risk of SSI due to reduced oxygen delivery to the tissues.

Other reported risk factors, such as female sex, peripheral vascular disease, tobacco use, diabetes mellitus, renal failure, type of surgery and urgency, preoperative ejection fraction, need for an intra-aortic balloon pump, and postoperative hyperglycemia were not associated with a statistically significant increased risk of infection in our study; however, this should not be construed as evidence that those factors are not associated with infection, particularly given the low number of infections in the cohort. ${ }^{25-28}$

As other studies have reported a risk modification of hyperglycemia by diabetes, we also investigated a possible interaction between diabetes and hyperglycemia but were likely limited by power. ${ }^{29-33}$ BMI, which is included in the multivariable model, is correlated with diabetes but as a continuous variable provides more power than diabetes. Differences in the definition of hyperglycemia in the literature may also partly explain why we did not find an association between hyperglycemia and risk of infection; in this study, we used a broad definition of hyperglycemia: a single occurrence of blood glucose greater than $180 \mathrm{mg} / \mathrm{dL}$ within 48 hours of surgery.

Although the organism data presented are limited by a low reporting rate, the nature of organisms isolated from these infections is nonetheless interesting for several reasons. First, there is a paucity of data of this nature reported in the literature. Second, one often makes the assumption that a secondary SSI will be the result of skin flora and very likely a Gram-positive organism; however, based on these limited data, we have shown that Gram-negative 
organisms and occasionally yeast are also isolated. This suggests that routine culture of these wounds should be considered to guide appropriate antibiotic coverage and that initial coverage should be appropriate for at least both Gram-positive and -negative organisms. Third, $S$ aureus was the most commonly isolated organism despite the fact that it was tested and identified preoperatively in $1194(55 \%)$ patients. The majority of these patients $(71 \%)$ received $S$ aureus prophylaxis.

A major interest of ours was to investigate the recently instituted process of care measures endorsed by numerous regulatory agencies, including the Centers for Medicare and Medicaid Services and the Joint Commission, on the incidence of secondary SSIs. In 2002, the Centers for Medicare and Medicaid Services implemented the Surgical Infection Prevention Project to decrease morbidity and mortality associated with postoperative SSIs. The key measures implemented to decrease SSIs as related to cardiac surgery include (1) administration of parenteral antimicrobial prophylaxis within 1 hour of incision ( 2 hours for vancomycin or fluoroquinolones), (2) discontinuation of prophylactic antimicrobials within 48 hours of cardiac surgery, (3) proper removal of hair, and (4) appropriate blood glucose control. ${ }^{34}$

There were not large enough differences in the timing of parenteral antimicrobial prophylaxis or proper removal of hair to allow comparison in this cohort, as virtually all patients had hair clipped and had prophylactic antibiotics administered appropriately. However, there was enough variability in duration of perioperative antibiotic therapy, type of antibiotic prophylaxis, and postoperative glycemic control to allow multivariable modeling that showed that practice variations in these factors were not associated with the development of a secondary SSI. Although one can argue that we were simply underpowered to show a difference in these practice variations, there is an alternative interpretation-even if these process-of-care measures are adhered to rigidly, the incidence of secondary SSI will never be zero. This lends support to the concept that, in major cardiac surgery, certain "never" events will never have a zero incidence, or that we are not looking at the correct combinations of process-of-care measures that will consistently prevent SSI events.

Perhaps the most interesting finding of our study is that, with patient follow-up to 65 days after the index operation, we were able to determine that the majority of secondary SSI were diagnosed after discharge from index hospitalization, and one quarter were diagnosed more than 30 days after the index operation. This later group would typically be missed in the Society of Thoracic Surgeons Adult Cardiac Surgery Database, as it only captures events to 30 days after the index operation.

In addition to the late occurrence of secondary SSIs, of those who developed a secondary SSI, the proportion of readmissions within 65 days of surgery was significantly greater than in those who did not develop a secondary SSI (34\% vs $17 \%, P<.01)$-and of those with a secondary SSI who were readmitted, more than $70 \%$ were readmitted because of the secondary SSI.

Although this study carries the strength of being a prospective cohort, there are several important limitations. First, although limiting the population to those patients with CABG and SVG conduit would imply that the secondary SSI reported was a saphenous vein graft harvest-site infection, the data point collected regarding secondary SSI did not differentiate between groin and leg. It is possible that what we presume to be SVG harvest-site infections were actually groin cannulation sites (also not captured explicitly). The patients most likely in question would be the 9 infections in those with a previous sternotomy. Unfortunately, it is impossible to discern this subtle difference from this dataset; however, we are confident that all reported secondary SSIs were of the groin or leg in patients that underwent CABG with SVG harvesting.

Second, although prospective, this study was not powered to examine the endpoint of secondary SSI, so its predictive power is limited. In this regard, our inability to show a benefit of any of the process-of-care variables could be due to lack of power. In addition, patients were not randomized to receive or not receive these measures, so there could be unobserved factors that were not measured or analyzed that explain our results. Third, our study unfortunately lacked data on method or outcome of treatment for secondary SSI. There was also limited data collected on vein harvest - we had no detail about who performed the vein harvest, the technique used for an open harvest, or whether an endoscopic harvest was attempted before converting to an open harvest. Use of drains, skin-closure techniques, and type of dressing were not collected for the secondary surgical incision, and these factors may affect the risk of infection. No scoring system, such as that developed by Elahi and colleagues, ${ }^{35}$ was used to assess the severity of the secondary SSIs.

Last, although overall follow-up was longer than in most registries and was $98 \%$ complete, events that occurred after 65 days would not have been identified. Occasionally follow-up was conducted by phone if patients refused to return for the follow-up visit. However, for the $2 \%$ of patients who did not have complete follow-up, a medical record search was conducted and any documented infectious complications were reported. Serious infections reported by phone or found in a medical record search were all adjudicated by an Event Adjudication Committee of experts in infectious diseases.

Despite close adherence to commonly practiced process of care measures, both deep and superficial secondary SSIs continue to be an important source of morbidity in patients who undergo CABG, frequently resulting in hospital readmission. Although we can identify patients at greater 
risk for these infections, such as those who undergo open harvesting of the saphenous vein, have a greater BMI, or receive more units of PRBCs, it is unlikely that the incidence of secondary SSI will ever be zero. Developing a better understanding of both patient factors as well as modifiable processes of care associated with secondary SSIs will help guide future endeavors focused on reducing the incidence of these morbid and costly complications.

\section{Conflict of Interest Statement}

Authors have nothing to disclose with regard to commercial support.

\section{References}

1. Gelijns AC, Moskowitz AJ, Acker MA, Argenziano M, Geller NL, Puskas JD, et al. Management practices and major infections after cardiac surgery. J Am Coll Cardiol. 2014;64:372-81.

2. Greco G, Shi W, Michler RE, Meltzer DO, Ailawadi G, Hohmann SF, et al. Costs associated with healthcare-associated infections in cardiac surgery. $J$ Am Coll Cardiol. 2017;65:15-23.

3. Williams JB, Peterson ED, Brennan JM, Sedrakyan A, Tavris D, Alexander JH, et al. Association between endoscopic vs open vein-graft harvesting and mortality, wound complications, and cardiovascular events in patients undergoing CABG surgery. JAMA. 2012;308:475-84.

4. Dacey LJ, Braxton JH, Kramer RS, Schmoker JD, Charlesworth DC, Helm RE, et al. Long-term outcomes of endoscopic vein harvesting after coronary artery bypass grafting. Circulation. 2011;123:147-53.

5. Paletta C, Huang D, Fiore A, Swartz M, Rilloraza F, Gardiner J. Major leg wound complications after saphenous vein harvest for coronary revascularization. Ann Thorac Surg. 2000;70:492-7.

6. Allen K, Griffith G, Heimansohn D, Robison RJ, Matheny RG, Schier JJ, et al. Endoscopic versus traditional saphenous vein harvesting: a prospective, randomized trial. Ann Thorac Surg. 1998;66:26-31.

7. Puskas JD, Wright CE, Miller PK, Anderson TE, Gott JP, Brown WM III, et al. A randomized trial of endoscopic versus open saphenous vein harvest in coronary bypass surgery. Ann Thorac Surg. 1999;68:1509-12.

8. Shahian DM, O'Brien SM, Filardo G, Ferraris VA, Haan CK, Rich JB, et al. The Society of Thoracic Surgeons 2008 Cardiac Surgery Risk Models: Part 1-Coronary Artery Bypass Grafting Surgery. Ann Thorac Surg. 2009;88(1 suppl): S2-22.

9. Lopes R, Hafley G, Allen K, Ferguson TB, Peterson ED, Harrington RA, et al. Endoscopic versus open vein-graft harvesting in coronary-artery bypass surgery. N Engl J Med. 2009;361:235-44.

10. Yun KL, Wu Y, Aharonian V, Mansukhani P, Pfeffer TA, Sintek CF, et al. Randomized trial of endoscopic versus open vein harvest for coronary artery bypass grafting: six-month patency rates. J Thorac Cardiovasc Surg. 2005;129:496-503.

11. Kiaii B, Moon BC, Massel D, Langlois Y, Austin TW, Willoughby A, et al. A prospective randomized trial of endoscopic versus conventional harvesting of the saphenous vein in coronary artery bypass surgery. J Thorac Cardiovasc Surg. 2002;123:204-12.

12. Andreasen JJ, Nekrasas V, Dethlefsen C. Endoscopic vs open saphenous vein harvest for coronary artery bypass grafting: a prospective randomized trial. Eur $J$ Cardiothorac Surg. 2008;34:384-9.

13. Schurr U, Lachat M, Reuthebuch O, Kadner A, Mäder M, Seiffert B, et al. Endoscopic saphenous vein harvesting for $\mathrm{CABG}$ - a randomized, prospective trial. Thorac Cardiovasc Surg. 2002;50:160-3.

14. Allen KB, Heimansohn DA, Robison RJ, Schier JJ, Griffith GL, Fitzgerald EB. Influence of endoscopic versus traditional saphenectomy on event-free survival: fiveyear follow-up of a prospective randomized trial. Heart Surg Forum. 2003;6:E143-5.

15. Allen K, Cheng D, Cohn W, Connolly M, Edgerton J, Falk V, et al. Endoscopic vascular harvest in coronary artery bypass grafting surgery: a consensus statement of the International Society of Minimally Invasive Cardiothoracic Surgery (ISMICS) 2005. Innovations. 2006;1:51-60.
16. Markar SR, Kutty R, Edmonds L, Sadat U, Nair S. A meta-analysis of minimally invasive versus traditional open vein harvest technique for coronary artery bypass graft surgery. Interact Cardiovasc Thorac Surg. 2010;10:266-70.

17. Ouzounian M, Hassan A, Buth KJ, MacPherson C, Ali IM, Hirsch GM, et al. Impact of endoscopic versus open saphenous vein harvest techniques on outcomes after coronary artery bypass grafting. Ann Thorac Surg. 2010;89: 403-8

18. Alexander J, Hafley G, Harrington R, Peterson E, Ferguson T, Lorenz T. Efficacy and safety of edifoligide, an E2F transcription factor decoy, for prevention of vein graft failure following coronary artery bypass graft surgery. JAMA. 2005;294: 2446-54.

19. Shroyer A, Grover FL, Hattler B, Collins JF, McDonald GO, Kozora E, et al. Onpump versus off-pump coronary-artery bypass surgery. N Engl J Med. 2009;361: 1827-37.

20. Zenati MA, Shroyer AL, Collins JF, Hattler B, Ota T, Almassi GH, et al. Impact of endoscopic versus open saphenous vein harvest technique on late coronary artery bypass grafting patient outcomes in the ROOBY (Randomized On/Off Bypass) trial. J Thorac Cardiovasc Surg. 2011;141:338-44.

21. Scrucca L, Santucci A, Aversa F. Regression modeling of competing risk using R an in-depth guide for clinicians. Bone Marrow Transplant. 2010;45:1388-95.

22. Rahmanian PB, Adams DH, Castillo JG, Chikwe J, Bodian CA, Filsoufi F. Impact of body mass index on early outcome and late survival in patients undergoing coronary artery bypass grafting or valve surgery or both. Am J Cardiol. 2007;100: $1702-8$

23. Waisbren E, Rosen H, Bader AM, Lipsitz SR, Rogers SO, Eriksson E. Percent body fat and prediction of surgical site infection. J Am Coll Surg. 2010;210: $381-9$.

24. Horvath KA, Acker MA, Chang H, Bagiella E, Smith PK, Iribarne A, et al. Blood transfusion and infection after cardiac surgery. Ann Thorac Surg. 2013;95: 2194-201.

25. L'Ecuyer PB, Murphy D, Little J, Fraser V. The epidemiology of chest and leg wound infections following cardiothoracic surgery. Clin Infect Dis. 2017:22:424-9.

26. DeLaria GA, Hunter JA, Goldin MD, Serry C, Javid H, Najafi H. Leg wound complications associated with coronary revascularization. J Thorac Cardiovasc Surg. 1981;81:403-7.

27. Utley JR, Thomason ME, Wallace DJ, Mutch DW, Staton L, Brown V, et al. Preoperative correlates of impaired wound healing after saphenous vein excision. $J$ Thorac Cardiovasc Surg. 1989;98:147-9.

28. Slaughter MS, Olson MM, Lee JT, Ward HB. A fifteen-year wound surveillance study after coronary artery bypass. Ann Thorac Surg. 1993;56:1063-8.

29. Greco G, Ferket BS, D'Alessandro DA, Shi W, Horvath KA, Rosen A, et al. Diabetes and the association of postoperative hyperglycemia with clinical and economic outcomes in cardiac surgery. Diabetes Care. 2016;39:408-17.

30. Swenne CL, Lindholm C, Borowiec J, Schnell AE, Carlsson M. Peri-operative glucose control and development of surgical wound infections in patients undergoing coronary artery bypass graft. J Hosp Infect. 2005;61:201-12.

31. Székely A, Levin J, Miao Y, Tudor IC, Vuylsteke A, Ofner P, et al. Impact of hyperglycemia on perioperative mortality after coronary artery bypass graft surgery. J Thorac Cardiovasc Surg. 2011;142:430-7.e431.

32. Furnary A, Wu Y. Clinical effects of hyperglycemia in the cardiac surgery population: the Portland Diabetic Project. Endocr Pract. 2006;12(suppl 3): 22-6.

33. Lazar HL, McDonnell M, Chipkin SR, Furnary AP, Engelman RM, Sadhu AR, et al. The Society of Thoracic Surgeons Practice Guideline Series: blood glucose management during adult cardiac surgery. Ann Thorac Surg. 2009; 87:663-9.

34. Bratzler D, Hunt D. The surgical infection prevention and surgical care improve ment projects: national initiatives to improve outcomes for patients having surgery. Clin Infect Dis. 2006;43:322-30.

35. Elahi MM, Haesey AM, Graham KC, Battula NR, Manketlow B, Dhannapuneni RR, et al. Leg wound infections following cardiac surgery: a scoring system for assessment and management. J Wound Care. 2005;14:337-40.

Key Words: surgical site infection, coronary artery bypass grafting, saphenous vein graft, postoperative length of stay, postoperative readmission, body mass index, red blood cell transfusion 


\section{APPENDIX E1. CARDIOTHORACIC SURGICAL TRIALS NETWORK (CTSN) MEMBERS}

The members of the CTSN involved in this study were as follows:

National Heart, Lung, and Blood Institute: Marissa A. Miller, Wendy C. Taddei-Peters, Dennis Buxton, Ron Caulder, Nancy L. Geller, David Gordon, Neal O. Jeffries, Albert Lee;

National Institute of Neurological Disorders and Stroke: Claudia S. Moy;

Canadian Institutes of Health Research: Ilana Kogan Gombos, Jennifer Ralph;

Network Chairs: Christiana Care Health System, Timothy J. Gardner, (Chair); Brigham and Women's Hospital, Patrick T. O'Gara, (Co-Chair);

Data Coordinating Center: International Center for Health Outcomes and Innovation Research at Icahn School of Medicine at Mount Sinai, Annetine C. Gelijns, Michael K. Parides, Deborah D. Ascheim, Alan J. Moskowitz, Ellen Moquete, Eric A. Rose, Melissa Chase, Yingchun Chen, Rosemarie Gagliardi, Lopa Gupta, Edlira Kumbarce, Ron Levitan, Karen O’Sullivan, Milerva Santos, Alan Weinberg, Paula Williams, Carrie Wood, Xia Ye;

Core Clinical Site Investigators: Cleveland Clinic Foundation, Eugene H. Blackstone (PI), A. Marc Gillinov, Pamela Lackner, Leoma Berroteran, Diana Dolney, Suzanne Fleming, Roberta Palumbo, Christine Whitman, Kathy Sankovic, Denise Kosty Sweeney; National Heart, Lung, and Blood Institute Clinical Research Scholars: Gregory Pattakos, Pamela A. Clarke; Columbia University, Michael Argenziano (PI), Mathew Williams, Lyn Goldsmith, Craig R. Smith, Yoshifumi Naka, Allan Stewart, Allan Schwartz; Daniel Bell, Danielle Van Patten; Duke University, Peter K. Smith (PI), Stacey Welsh, John H. Alexander, Carmelo A. Milano, Donald D. Glower, Joseph P. Mathew, J. Kevin Harrison; National Heart, Lung, and
Blood Institute Clinical Research Scholars: Mark F. Berry, Cyrus J. Parsa, Betty C. Tong, Judson B. Williams; East Carolina Heart Institute, T. Bruce Ferguson (PI), Alan P. Kypson, Evelio Rodriguez, Malissa Harris, Brenda Akers, Allison O'Neal; Emory University, John D. Puskas (PI), Vinod H. Thourani, Robert Guyton, Jefferson Baer, Kim Baio, Alexis A. Neill; Montefiore-Einstein Heart Center, Robert E. Michler (PI), David A. D'Alessandro, Joseph J. DeRose, Jr, Daniel J. Goldstein, Ricardo Bello, William Jakobleff, Mario Garcia, Cynthia Taub, Daniel Spevak, Roger Swayze; Montreal Heart Institute, Louis P. Perrault (PI), Arsène-Joseph Basmadjian, Denis Bouchard, Michel Carrier, Raymond Cartier, Michel Pellerin, Jean François Tanguay, Ismael El-Hamamsy, André Denault, Jonathan Lacharité, Sophie Robichaud; NIH Heart Center at Suburban Hospital, Keith A. Horvath (PI), Philip C. Corcoran, Michael P. Siegenthaler, Mandy Murphy, Margaret Iraola, Ann Greenberg; University of Pennsylvania, Michael A. Acker (PI), Y. Joseph Woo, Mary Lou Mayer; University of Virginia, Irving L. Kron (PI), Gorav Ailawadi, Karen Johnston, John M. Dent, John Kern, Jessica Keim Sandra Burks, Kim Gahring;

Protocol Review Committee: David A. Bull (Chair); Patrice Desvigne-Nickens, Executive Secretary; Dennis O. Dixon, Mark Haigney, Richard Holubkov, Alice Jacobs, Frank Miller, John M. Murkin, John Spertus, Andrew S. Wechsler;

Data and Safety Monitoring Board: Frank Sellke (Chair); Cheryl L. McDonald, Executive Secretary; Robert Byington, Neal Dickert, Dennis O. Dixon, John S. Ikonomidis, David O. Williams, Clyde W. Yancy;

Medical Monitors: James C. Fang, Wayne Richenbacher;

Overall Event Adjudication Committee: Vivek Rao (Chair); Karen L. Furie, Rachel Miller, Sean Pinney, William C. Roberts;

Infection Event Adjudication Committee: Rachel Miller (Chair); Shirish Huprikar, Marilyn Levi. 